\title{
Negatividad, utopía y metasonidos: modelos musicales para la filosofía de Adorno a Lachenmann
}

\author{
ANTONIO NOTARIO RUIZ \\ Universidad de Salamanca
}

La verdadera crítica consiste en potenciar la obra o el autor estudiados, convirtiéndolos en tipo de una forma especial de humanidad y obtener de ellos, por este procedimiento, un máximun de reverberaciones culturales.

José Ortega y Gasset

EN El FRAGMENTO 143 DE mINIMA MORALIA, Adorno enuncia la posibilidad de que el concepto estricto y puro del arte sólo quepa extraerlo de la música, por cuanto que en la gran literatura y la gran pintura-la grande precisamente-hay implícito un componente material que desborda la jurisdicción estética sin quedar disuelto en la autonomía de la forma ${ }^{1}$. No es desdeñable el intento permanente de Adorno por contrapesar las condenas y hostilidades que ha sufrido el arte musical a lo largo de la historia, siendo relegado al último lugar de las jerarquías artísticas o incluso excluyéndolo de ellas. Pero más allá de ese posible programa oculto adorniano, la relevancia de este fragmento se encuentra en relación con la música contemporánea y con la emancipación del sonido. Y no me refiero sólo a la música contemporánea de Adorno sino a la composición musical actual. Tomando como referencia las obras no de los compositores de la denominada Escuela de Viena sino de Carola Bauckholt, José Luís de Delás, Francisco Guerrero, Manuel Hidalgo, Helmut Lachenmann, Gyorgy Ligeti, Ángel Liz, Luigi Nono, Salvatore Sciarrino, Mauricio Sotelo y Karlheinz Stockhausen

1 Th. W. Adorno, Minima moralia, tr. J. Chamorro Mielke, Madrid: Akal, 2004, p. 23. Cito las obras traducidas en la edición de Obras Completas en español de Akal y las no traducidas en la edición alemana con la abreviatura GS: Th. W. Adorno, Gesammelte Schriften. Hg. von Rolf Tiedemann, Gretel Adorno, Susan Buck-Morss und Klaus Schultz Frankfurt: Suhrkamp, $1970-1986$. 
como representativas de tendencias propiamente nuevas, nos encontramos con la emergencia de un concepto diferente de música, con una conciencia inédita de lo sonoro y también, por lo tanto, con la posibilidad de una relectura de los textos de Adorno. En las obras de los compositores citados, especialmente en la denominada «música concreta con instrumentos convencionales» se plasma ese «concepto estricto y puro del arte» que menciona Adorno de forma más radical todavía que en la música que él tomó como modelo. En definitiva, los compositores y las obras de las tendencias más comprometidas con la novedad de los últimos años nos permiten actualizar a Adorno.

Con ese objetivo, el título de este artículo es una variación sobre un parágrafo de Teoría Estética. La variación, al modo musical de Alban Berg, aporta la novedad del término metasonido pero mantiene los dos pilares del pensar adorniano: la negatividad y la utopía. Se trata de tomar alguno de los conceptos y reflexiones adornianos con la intención de actualizarlos, de «hacer vivir al clásico» que ya es Adorno. En ese sentido, se trata al mismo tiempo, tanto de la propuesta de releer a Adorno como de leer la composición musical y la creación sonora actuales a la luz de sus aportaciones a la estética.

En este caso, y pensando en las obras de los compositores citados y de tantos otros que se podrían añadir, se puede enlazar con la nada desdeñable vertiente política de la estética adorniana. La posibilidad de la utopía está ligada al arte musical, entre otros aspectos, en el de la escucha. Adorno detalla en distintos momentos de su obra la importancia de la escucha como vía de acceso a la libertad frente a la escucha atomizada que propicia la industria cultural -multiplicada exponencialmente en nuestros días por el efecto mp3 y otros compresores del sonido digital- y la cosificación de los productos facturados como "música"2. Una escucha que rompa con esos límites sólo es posible mediante una paciente enseñanza, una educación, en este caso, para la emancipación auditiva. Y en esa emancipación, el individuo puede encontrarse con la complejidad de lo sonoro, con la infinita gama de matices y con la azarosa red de constelaciones rítmicas y tímbricas. Esa emancipación es posible, pero dificultosa, lenta y permanentemente obstaculizada por el dialecto tonal impuesto desde los medios en todos los formatos posibles. La ruptura con la identidad tonal global es, en este sentido, una ruptura plenamente política y por eso es anatematizada conveniente y permanentemente como elitista, como ajena al público. La libertad auditiva se convierte en un camino preferente ha-

2 Th. W. Adorno, «Instrucciones para la audición de la nueva música», en: El fiel correpetidor. Madrid: Akal, 2007, pp. 197-259; «Typen musikalischen Verhaltens», en Einleitung in die Musiksoziologie: Zwölftheoretische Vorlesungen. Frankfurt: Suhrkamp, 1973, GS 14, 178-198; «Über den Fetischcharakter in der Musik und die Regression des Hörens», en: Dissonanzen, Frankfurt: Suhrkamp, GS 14, 1973, 1980, pp. 14-50. 
cia el territorio de la utopía, de la cual no se pueden realizar imágenes. De ahí la preferencia que Adorno concede a la música al conjuntar tanto el elemento emancipatorio como la ausencia de imágenes, algo que conviene completamente a la invisibilidad de las imágenes sonoras. Lo que se siente como utopía es sólo la negación de lo existente y depende de ello. Está en el centro de las antinomias contemporáneas el que el arte deba y quiera ser utopía con tanta mayor decisión cuanto que ésta queda obstruida por la realidad funcional y, por el otro lado, para no traicionar a la utopía en el resplandor y consuelo que le son propios, que no pueden llegar a serlo3.

\section{RELEER A ADORNO}

Aunque la filosofía y la música han estado estrechamente relacionadas desde, al menos, la época presocrática, ha sido especialmente a partir del momento en que comenzó a florecer lo que Marcel Brion denomina como el «alma romántica», cuando los caminos entrelazados de ambas han alcanzado territorios antes no conquistados ${ }^{4}$. Sabido es que Hegel, por ejemplo, sintió una inclinación creciente por la música a lo largo de su vida. No sólo fue testigo poco antes de su muerte del «estreno» de la Pasión según San Mateo de Johann Sebastian Bach rescatada del olvido y dirigida por Felix Mendelssohn ${ }^{5}$, sino que en la última serie de lecciones sobre Filosofía del Arte, las consideraciones sobre música habían ganado en precisión técnica y profundidad filosófica ${ }^{6}$. Schopenhauer de una forma y Nietzsche de otra, son difícilmente comprensibles sin un conocimiento y una experiencia musical previas, además de un cierto conocimiento de las óperas de Richard Wagner. Soren Kierkegaard, que tanto interés despertó en Adorno y en Bloch, dedicó numerosas páginas a la música en general y a la ópera Don Giovanni de Mozart en particular. Más adelante, tanto Wilhelm Dilthey como Edmund Husserl, desde principios diferentes, han concedido una gran importancia a la música y a lo sonoro respectivamente. Más cerca de nuestros días, por último, Gilles Deleuze y Michel Foucault, amigos y compañeros de Jean Barraqué y de Pierre Boulez, han concedido gran importancia a la música

3 Cfr. Lo nuevo, la utopía, la negatividad en: Th. W. Adorno, Teoría Estética, Madrid: Akal, 2004, p. 50. Ibid. Opción política, p. 334.

4 M. Brion, Schumann et l'âme romantique, Paris: Albin Michel, 1954.

5 D. Bourel, Moses Mendelssohn. La naissance du judaïsme moderne, Paris: Gallimard, 2004, p. 11

6 G. W. F. Hegel, La música. Extracto de los cursos de estética impartidos en Berlín en 1828/29, según el manuscrito de Karol Liebelt. Texto establecido por Annemarie GethmannSiefert, en: Anuario Filosófico. XXIX/1, 1996, pp. 196-232. 
en sus filosofías ${ }^{7}$. De manera que no parece exagerado afirmar que la experiencia estética moderna y sus diferentes codificaciones teóricas deben mucho a la música, así como la filosofía de los dos últimos siglos, que especialmente en los últimos años también se ha nutrido abundantemente del arte sonoro.

En ese contexto de relación entre ambos haceres, es insoslayable el caso del pensamiento de Theodor Wiesengrund Adorno (1903 - 1969), aunque todavía no exista consenso académico sobre el valor de la música en su filosofía. Desde hace tiempo, defiendo la tesis de que Adorno es un compositor que pertenece al grupo de músicos del círculo de Arnold Schönberg (1874-1952) -la Segunda Escuela de Viena, para muchos-y que desde esa pertenencia es desde la que ha llevado a cabo su esfuerzo intelectual y teórico en ámbitos tangentes: la estética, la filosofía, la sociología y la propia música convertida en praxis. No es, por tanto, un «musicólogo» en el sentido convencional ni actual del término, ni un «sociólogo de la música» sino un compositor filósofo ${ }^{8}$.

En los últimos años, coincidiendo con las repercusiones del centenario de su nacimiento, se ha renovado el interés por la filosofía de Th. W. Adorno. De forma parcialmente independiente respecto a la recepción en Alemania, se han realizado aproximaciones en España que han roto con la imagen, que parecía ser inamovible, de Adorno. Esa imagen había quedado establecida por una pretendida ortodoxia más interesada en desactivar y embalsamar el pensamiento adorniano que en actualizarlo. Trabajos como los de Susan BuckMorss, Jürgen Habermas, Martin Jay o Max Paddison tuvieron su influencia clara en España a través de las correspondientes traducciones y de trabajos que no cuestionaban esa mirada, como los de Mercé Rius o Raúl Gabas ${ }^{9}$. Frente a ese tipo de estudios que ocultaban a Adorno tras diferentes tópicos no contrastados documentalmente, intentando condenarlo a la imposible continuidad, los trabajos de Mateu Cabot, Vicente Gómez y José Antonio Zamora entre otros, han contribuido a recuperar el potencial crítico del pensamiento adorniano y a su percepción en el ámbito filosófico español ${ }^{10}$.

7 Cf. R. Pinhas, Les larmes de Nietzsche. Deleuze et la musique, Paris: Flammarion, 2001.

8 G. Vilar, «Composición: Adorno y el lenguaje de la filosofía», en: Isegoría, Madrid, $\mathrm{n}^{\circ}$ 11, abril, 1995; G. Vilar, «Adorno y Beethoven. Filosofía de la música», en: La Balsa de la Medusa, no 32, 1994; E. Fubini, La estética musical desde la Antigüedad hasta el siglo XX, tr. C. G. Pérez de Aranda, Madrid: Alianza, 2002.

9 S. Buck-Morss, Origen de la dialéctica negativa. Theodor W. Adorno, Walter Benjamin y el Instituto de Frankfurt, México: Siglo XXI, 1981; M. Jay, Adorno, London: Fontana Paperbacks, 1984. Hay traducción española: M. Jay, Adorno, tr. M. Pascual Morales, Madrid: Siglo XXI, 1988; M. Paddison, Adorno's Aesthetic of Music, Cambridge: Cambridge University Press, 1995; M. Rius, T. W. Adorno. Del sufrimiento a la verdad, Barcelona: Laia, 1985.

10 M. Cabot, El penós camí de la raó. Theodor W. Adorno i la crítica de la modernitat, Palma: Universitat de les Illes Balears, 1997; V. Gómez, El pensamiento estético de Theodor W. 
Con esa tarea de recuperación, intensificada en Alemania desde el año del centenario de Adorno, ha confluido el esfuerzo editorial para publicar el mayor número posible de textos adornianos no recogidos en las Obras Completas, así como las partituras de las composiciones musicales de Adorno ${ }^{11} \mathrm{y}$ las correspondientes grabaciones discográficas. A la necesidad de acercarse a Adorno no como filósofo-músico sino como músico-filósofo ahora se puede añadir la reclamación de la necesidad de una atención rigurosa a las composiciones de Adorno, no sólo para dejar en evidencia la cuestionabilidad del Adorno construido por Buck-Morss, Jay o Paddison, sino como afirmación de la centralidad del trabajo compositivo para el filósofo francfortiano. Efectivamente, el análisis musical y la composición no fueron un entretenimiento de burgués acomodado, de diletante al viejo estilo, sino que constituyeron un auténtico núcleo en la formación del pensamiento adorniano antes incluso de que abordara su segundo trabajo de habilitación que, como es sabido, versaba sobre Kierkegaard. La música fue para el joven Adorno -entre 1925 y 1929- una auténtica praxis. Esa es una de las tesis que defiendo en este trabajo. Una tesis que supone una nueva vía de acceso a Adorno y que es clave, por una parte, para la comprensión de su filosofía y de la evolución de la misma. Pero al mismo tiempo, es clave para poder articular una filosofía de la música que tome a Adorno como punto de partida. Al desarrollo de estos dos aspectos se dedica este trabajo.

\section{Das Komponieren ist doch die bestimmende geistige Realität für mich ${ }^{12}$}

Esta frase se podría leer como un intento de Adorno por quedar bien con su maestro. Pero el resto de la correspondencia así como lo que se conoce del autor de Wozzeck y Lulú no avalan esa interpretación. Al contrario, lo que sí está establecido es que los tres compositores vieneses -Schönberg, Webern y Berg- habían adoptado una visibilidad social cercana a la de una secta o un círculo esotérico muy cerrado. Arnold Schönberg ejercía como un auténtico gurú respetado e incluso reverenciado por los demás. Tanto Berg como Webern podrían haber reclamado la prioridad en el alumbramiento del atonalismo libre, pero un consenso tácito mantuvo a Schönberg como figura principal del trío.

Adorno, Valencia, Cátedra, 1998; A. Notario Ruiz, La visualización de lo sonoro, Salamanca: Universidad de Salamanca, 2002; J. A. Zamora, Th. Adorno. Pensar contra la barbarie, Madrid: Trotta, 2004.

11 Th. W. Adorno, Kompositionen. Herausgegeben von Heinz-Klaus Metzger und Rainer Riehn. München: Edition text + kritik, 3 v. 1980, 2007. Tiedemann, Rolf (Hg.), Fankfurter Adorno Blätter I-VIII. München: Edition text+kritik, 1992, 2001.

12 Carta de Adorno a Berg de 28 de junio de 1926, en Theodor W. Adorno-Alban Berg Briefwechsel 1925 -1935, Herausgegeben von Henri Lonitz, Frankfurt: Suhrkamp, 1997, p. 89. 
De hecho, sólo Hanns Eisler y Adorno cuestionaron el desenvolvimiento del grupo. Adorno, que conoció a Eisler en Viena y analizó y escribió sobre sus obras, no compartía totalmente la opción eisleriana: el comunismo militante. Sin embargo, él mismo se define como comunista y reclama el carácter político de la composición. En ese contexto, critica el concepto mismo de escuela aplicado al trío vienés. Y, por supuesto, comienza a denunciar las tendencias reaccionarias por su contenido político: el falseamiento de la realidad, la oferta de una falsa modernidad, en definitiva, la reducción del individuo a los comportamientos que ya habían fenecido junto a la música tonal.

¿Cómo llega Adorno a esa afirmación? El punto de partida de Adorno se puede establecer en su infancia y su formación musical inicial. Después de haber crecido en un ambiente familiar y social marcadamente musical, a comienzos de la década de los veinte, Adorno ya estaba en posesión de un conocimiento profundo de la música anterior y de la que se estaba escribiendo en el mismo momento. ¿Es indiferente este dato a la hora de pensar en sus estudios y lecturas filosóficas? Pienso que no. El comienzo de su formación filosófica no interfiere su vida musical ni la retrasa, como manifiestan las anotaciones citadas. De hecho, su evolución musical parece independiente de sus incipientes inquietudes filosóficas. Así, a pesar de conocer el Pierrot lunaire de Arnold Schönberg desde 1922, Adorno busca algo más que sólo cree encontrar en las obras de Paul Hindemith. En un comentario a propósito del estreno en Francfort de la ópera Sancta Susana op. 21 de dicho compositor, lo señala como el que le ofrece lo que la música anterior no le ofrecía:

Hindemith mantiene una relación muy íntima con la realidad, con una realidad que en la música ha ido perdiendo cada vez más su dignidad y su autonomía: bien porque, como ocurre en Brahms, se haya hundido en el abismo de la interioridad subjetiva; bien porque, como ocurre en Strauss, es representada en su materialidad desligada del yo, por analogías psicológicas; bien porque, como ocurre en Debussy, sea aprehendida como mero reflejo del yo. Pero en Hindemith se anuncia la aspiración a insertar la realidad como un componente válido dentro del contexto de la consciencia ${ }^{13}$.

Prudentemente, Adorno habla sólo de lo que se anuncia en Hindemith, pero sin desoír otros elementos no tan prometedores como sus carencias técnicas musicales o su frivolidad a la hora de componer. Pero lo más importante de este texto es que se enuncian ya algunos aspectos de lo que será posteriormente nuclear en el pensamiento musical adorniano, tales como el problema de la autonomía del arte, el de la realidad -categoría difusa todavía en este artículo- y,

13 Th. W. Adorno, Ad vocem Hindemith, en Impromptus. GS 17, pp. 216-217. 
sobre todo, por ser el que aparece expresado con una conciencia más clara, el de una incipiente filosofía de la historia de la música. Desde ella lleva a cabo Adorno la contraposición entre el subjetivismo brahmsiano, el mero materialismo de Richard Strauss o el subjetivismo de Claude Debussy, que alcanza en otros párrafos al «gesto bárbaro» de los rusos, con Stravinsky a la cabeza y sus seguidores franceses, o a la «conciencia trágica» de Schönberg ${ }^{14}$. Con sólo diecinueve años, Adorno estaba, por lo tanto, perfectamente orientado en el doble sentido de saber dónde se encontraba en relación con la música de su momento y también de cuál era la dirección que quería seguir. Y es que no se debe olvidar que ya en su artículo sobre el expresionismo había dejado clara su conciencia de la crisis del arte en general que afectaba, obviamente, a la música:

El arte de la época se enfrenta a la cuestión de la continuación de su existencia ${ }^{15}$.

Esa orientación se plasma en el resto del artículo sobre Hindemith en el que Adorno se ocupa de otro de los problemas que más intensamente han ocupado a los teóricos y a él mismo: el de la forma. Afirma, por ejemplo, que

...el problema de la forma, que es aquí el problema central, repercute también en las siguientes composiciones instrumentales de Hindemith ${ }^{16}$.

En mi opinión, lo que atraía musicalmente a Adorno del joven Hindemith -aparte de una conjeturable espontaneidad tanto personal como compositiva, que contrastaba con su reconocida seriedad y timidez de aquel momento ${ }^{17}$ - es su capacidad formal no enraizada en la tradición, sino completamente ecléctica y heterodoxa. Adorno ya había escrito para cuarteto de cuerda cuando escribió este artículo y había comenzado a experimentar las dificultades de la forma musical en la creación misma, y no sólo desde el punto de vista de la crítica y de la teoría.

Porque cuando Adorno escribe esa carta, ya no es sólo un estudiante de composición y de filosofía a la par que un crítico musical, sino que es ya compositor. Entre 1922 y 1926 ya había escrito algunas de las obras que podemos tomar en consideración y trabajaba en otros proyectos compositivos nuevos. Pero, lo que es más importante, en aquel momento quiere dedicarse a la composición.

14 Op. cit., p. 213.

15 Op. cit., p. 235.

16 Ibid., pp. 215-216. El subrayado es mío.

17 M. Jay, La imaginación dialéctica, tr. J. C. Curutchet, Madrid: Taurus, 1974, p. 55. Adorno habla de su 'bestial seriedad' (tierisch ernst), GS 13, pp. 361. 
Efectivamente, del total de las composiciones musicales de Adorno, más de media docena están compuestas entre 1925 y $1930^{18}$. Algunas son anteriores y se trata en realidad de esbozos compositivos, de ejercicios de estilo de un estudiante avanzado de las disciplinas creativas de la música: la armonía, el contrapunto y la composición misma. Pero en 1924 se había producido un hecho que resultó ser clave en su vida, al que hay que conceder una importancia mayor, a mi juicio, de la que se le ha concedido hasta ahora: la audición de los Tres fragmentos de Wozzeck, compuestos por Alban Berg y dirigidos por Herman Scherchen. A partir de ese momento, la relación de Adorno con la música en general y con la composición en particular -que ya había comenzado a estudiar con Bernhard Sekles en Frankfurt-, cambió radicalmente. El contacto con Alban Berg, no sólo como alumno, se va a convertir en uno de los pilares de su evolución. La música, de la mano de Berg, pasó a convertirse en el eje de su trabajo intelectual, de forma que su dedicación a la filosofía quedó en un segundo plano. Consideraba sus trabajos filosóficos como trámites, como ejercicios de ocasión relacionados con la habilitación que, en la correspondencia con Berg, no parece interesarle demasiado. Durante esos años, al menos, Adorno se leyó a sí mismo como músico. Y como músico perteneciente a lo que se viene denominando Escuela de Viena. En esa misma pertenencia se encuentra tanto la respuesta a algunas de las preguntas que Adorno ya se había planteado con anterioridad en sus primeros artículos de crítica musical, como la fuente de nuevos problemas que, en muchos casos, van a estar presentes en su pensamiento permanentemente desde entonces. Tanto en las respuestas como en los problemas, Adorno va a nutrir al propio círculo vienés de un armazón intelectual del que carecía. Y en la construcción de esa defensa teórica de la forma de entender la música por parte de los padres del atonalismo, va a encontrar Adorno también la vinculación entre música y filosofía. Desde ese momento, Adorno va a proponer modelos musicales para la filosofía, especialmente Alban Berg y Gustav Mahler.

Adorno va a explorar, además, otros temas de la estética musical que ya no dejarán de estar presentes en sus escritos. Por ejemplo, otro de los elementos que analizaba Adorno en el artículo sobre Hindemith que he comentado anteriormente, es el de los textos elegidos por Hindemith para sus óperas, que, en general, dejaban bastante que desear, tanto desde el punto de vista de los temas como del de la calidad literaria. No es de extrañar, por eso, que el texto de Georg Büchner adaptado por Alban Berg en Wozzeck, sedujera la sensibilidad literaria

18 Cfr., entre otras, Vier Gedichte von Stefan George für Singstimme und Klavier op. 1, 1925-1928; Vier Lieder für eine mittlere Stimme und Klavier op. 3. 1928; las tres primeras Bagatelas del ciclo Sechs Bagatellen für Singstimme und Klavier op. 6, en: Th. W. Adorno, Kompositionen, op. cit. 
de Adorno, al tiempo que la música del compositor vienés le ofreciera lo que la de Hindemith prometía sin llegar a conceder. De hecho, el problema de la relación entre el texto y la música también pasó a ser uno de los que ocuparon a Adorno desde aquellos años.

Y es que en el primer tramo de la vida musical de Adorno todavía no existía una conciencia clara de la novedad musical, sino sólo la necesidad de la misma. La preferencia por Hindemith, fundada en hipotéticas razones personales más que en las estrictamente musicales, es precisamente un síntoma de esa «necesidad» de Adorno de algo diferente. Las temporadas francfortianas de ópera ofrecían ya entonces el repertorio habitual con una primacía clara de los títulos alemanes. Ese repertorio estaba formado por obras tonales, con una estructura dramática convencional y unos contenidos muy queridos por el público burgués de finales del XIX y comienzos del XX: tragedias en torno a las relaciones amorosas, exotismo, temas históricos trivializados, etc. ${ }^{19}$. Por otra parte, la escasa difusión de las obras atonales las convertía en algo prácticamente inaccesible. El mencionado Pierrot lunaire de Schönberg no fue, a nuestro juicio, un buen punto de partida para adentrarse en el atonalismo en aquel momento. Y no podía serlo porque lo que Adorno no conocía todavía entonces era el dodecafonismo, que no comenzó a hacerse público hasta 1925 y de forma muy restringida. No cabe duda de que el impacto de la versión bergiana de los principios de la Escuela de Viena, unido al encanto personal del propio Alban Berg jugaron un papel importante en la decisión de Adorno de trasladarse a Viena para continuar sus estudios de composición con él. Pero a esos factores hay que añadir, sin duda, el hecho de que es el surgimiento de la «composición con doce sonidos» lo que va a permitir a Adorno establecer cuál es la situación de la composición y, por lo tanto, de la música en aquel momento. El giro de Schönberg y, con todos los matices, de Berg y Webern, convirtiendo en pasado cerrado la etapa atonal que ellos mismos habían alumbrado, supone el cierre de un ciclo y, al mismo tiempo el comienzo de otro. Adorno va a cobrar conciencia al trasladarse a Viena de lo que ha supuesto ese primer cuarto de siglo para la historia de la música occidental. Y va a cobrar conciencia también de las contradicciones internas del círculo de compositores vieneses. De ahí que cuestione muy pronto el concepto mismo de «escuela», apoyándose en las propias teorías de Schönberg. Éste, con su nuevo método, se convierte en el punto de fuga que permite contemplar en perspectiva las diferentes tendencias musicales. Y Adorno ve con claridad que en 1925 hay una componente política en todo lo que está sucediendo en el ámbito de la composición y en la propia «escuela» vienesa. No cabe duda de que el caso Eisler y el marxismo peculiar de Benjamin, o su

19 Para consultar las críticas de conciertos y representaciones de óperas escritas por Adorno desde el mes de febrero de 1922, $c f$. Th. W. Adorno, GS 19, pp. 9-280. 
contacto incluso personal con Lukács, desempeñaron un papel importante en esa lectura política de la realidad musical ${ }^{20}$. Una realidad en la que, a lo largo de los años veinte, se iban a establecer tendencias cada vez más conservadoras $y$, en muchos casos, reaccionarias y filo fascistas. Arnold Schönberg, aspirante a burgués, y tal vez condicionado por el problema de la asimilación que le había llevado incluso a bautizarse como católico -aunque retornara más adelante al judaísmo- no quería tener que ver nada con la política y mucho menos con la izquierda. Si la ruptura con Eisler supuso la apertura de un debate en torno a la posibilidad misma de la vanguardia musical en una sociedad escindida en la que la opresión del proletariado y de todos los ciudadanos marginados era un hecho insoslayable, la crisis que abrió y vivió Adorno entre noviembre de 1925 y junio de 1926, supuso el cuestionamiento no de la posibilidad misma de esa vanguardia sino la de su desenvolvimiento, su desarrollo y su función en esa misma sociedad escindida.

Adorno supo ver en el grupo vienés de Schönberg mucho más de lo que el compositor y sus alumnos alcanzaron a vislumbrar. No es sólo, como pretenden algunos analistas, que Adorno descubriera en su estancia en Viena que teoría y práctica musical deben confluir en una auténtica praxis. Es, también, la toma de conciencia de que la conquista de la atonalidad suponía un momento histórico de marcado contenido político y con importantes consecuencias para la continuidad de la institución música. Adorno vió en el atonalismo un auténtico paradigma de pensamiento y de sociedad, sobre todo en la versión de su maestro Alban Berg, en la que ese atonalismo aparecía entrelazado en dosis armónicamente asimétricas con otros lenguajes. Una buena prueba del alcance del atonalismo, insospechado alcance, para sus propios mentores es el hecho de que ellos mismos se leyeran como continuadores de la tradición, algo que es cierto, pero que ellos entendieron como solamente un paso más en una gran corriente histórica y no como una fisura, como una vía que desembocaba en otro camino: el camino hacia el sonido mismo.

El otro argumento de la relevancia del momento atonal es el paso atrás que se sustancia en la sistematización del atonalismo, de forma que las relaciones arbitrarias del sistema tonal son sustituidas por las relaciones rígidas del atonalismo sistematizado o dodecafonismo. Quedaba abolida, sí, la jerarquía

20 Sobre la peculiaridad del marxismo de Walter Bewnjamin, cf. G. Scholem, Walter Benjamin. Historia de una amistad, tr. de J. F. Yvars y V. Jarque, Barcelona: Random House Mondadori, 2007, pp. 192 y ss. Sobre la ruptura de Eisler con Schönberg, cf. A. Betz, Hanns Eisler. Música de un tiempo que está haciéndose ahora mismo, tr. de A. F. Mayo, Madrid: Tecnos, 1994, pp. 52-57 y H. H. Stuckenschmidt, Schönberg. Vida, contexto, obra, tr. A. Agud, Madrid: Alianza, 1991, pp. 262-263. Sobre el encuentro de Adorno con Lukács, $c f$. Carta de Adorno a Berg de 21 de junio de 1925, en: Theodor W. Adorno-Alban Berg Briefwechsel 1925 - 1935. Herausgegeben von Henri Lonita, Frankfurt: Suhrkamp, 1997, p. 17. 
caprichosa disfrazada de naturaleza que se había reclamado para el sistema tonal - una ideología, una teoría pseudo científica bien anclada en el racionalismo cartesiano- pero se recuperaba la necesidad de reglamentar las relaciones entre los sonidos. Se perdería, por tanto, al seguir ese camino la absoluta libertad del atonalismo.

La historia de la música se bifurcó en aquel momento. La línea pretendidamente progresiva que habría avanzado hasta el dodecafonismo dio lugar a una pseudo vanguardia obsesionada por el hecho en sí de la relación entre sonidos. De ahí nacería posteriormente la rigidez del serialismo integral. El atonalismo libre, por otra parte, fue a confluir con otros movimientos artísticos emancipadores y libertarios que concederían cada vez más protagonismo al sonido mismo y a elementos que no podrían encontrar acomodo en los discursos musicales.

Esa bifurcación de la historia de la música no ha sido contemplada ni recogida por la institución música. Al contrario, la reacción antivanguardista no va a distinguir entre una y otra tendencia sino que va a agrupar torticeramente todo lo no «agradablemente tonal» como un solo movimiento: lo que atenta contra el buen gusto, el buen sentido y la siempre mencionada universalidad del lenguaje musical. El rechazo en bloque de todo lo nuevo va a dar paso en pocos años, a la aceptación de determinados dialectos musicales que, tras la apariencia de ruptura suponen sólo una tímida reforma que ya estaba implícita en los compositores del último tercio del siglo XIX. Es decir, comienza muy pronto a generalizarse la tergiversación de que existe un arte contemporáneo aceptable y otro que no. Stravinsky, rechazado ruidosamente en el teatro de los Campos Elíseos con motivo del estreno de La consagración de la primavera en 1913, se va a convertir en poco tiempo, en el referente por excelencia de lo moderno tolerable. Stravinsky, todavía hoy celebrado por los herederos de la reacción como el padre de la modernidad musical, es una consecuencia lógica y me atrevo a decir que inevitable, de la confluencia entre las grandes construcciones mal llamadas nacionalistas de su Rusia natal y los líricos arabescos debussystas. La riqueza de su acento, propiamente personal y nada fácil -aunque no imposible- de imitar, demuestra su límite en la imposibilidad de su universalización: Stravinsky sólo hay uno, los demás son imitadores. El atonalismo, por el contrario, abre la puerta a muchas y diversas formas de entender la creación musical y sonora. El joven Adorno se mantendrá en la ambigüedad y en la duda entre las dos vías, aunque más en el plano teórico que en el creativo, ya que no dudó en componer dodecafónicamente.

No hay que perder de vista que después de la Segunda Guerra Mundial la vanguardia alemana quedó especialmente mutilada: Schönberg, Eisler, Weill, Kolisch, Scherchen entre otros, pudieron exiliarse. Krasa, Schulhoff, Ullmann, Haas y otros muchos acabaron sus días en los campos de exterminio nazis. Para colmo de males, Alban Berg había fallecido en 1935, y Anton Webern en 
1945. El silencio de la nueva música fue total. Los compositores del régimen nacionalsocialista, al igual que los italianos y los españoles más tarde, pero también los soviéticos, se entregaron a un arte oficial, teñido de elementos nacionales, de ritmos marciales, de ampulosidad retórica y de un despliegue desproporcionado de medios y materiales. Richard Strauss, Carl Orff, Paul Hindemith y, por supuesto, Richard Wagner, fueron los mitos del público acomodado a la nueva situación.

El otro núcleo considerado por algunos como vanguardista, el francés, tampoco salió indemne de las nuevas circunstancias. La frivolidad estética y el neoclasicismo de la década de los veinte no podían seguir vigentes después de la crisis del 29 y de las convulsiones políticas de Francia. Algunos compositores ajenos al «Grupo de los Seis» abandonaron el país -como Edgar Varèse - y otros continuaron su labor con dificultades similares a las de sus colegas centroeuropeos, como Olivier Messiaen que, de hecho, se convirtió en el nexo entre dos generaciones.

Finalizada la guerra, la desolación general alcanzaba, por supuesto, a la composición. El vacío de más de una década había dado lugar a una situación singular: la mayor parte de los compositores europeos -y también muchos instrumentistas- se encontraban exiliados en América -los compositores alemanes, austriacos, checos, etc. optaron en general por los Estados Unidos, mientras que los españoles y algunos franceses lo hicieron por Argentina, Brasil y México-. En esos países de acogida desarrollaron una intensa labor pedagógica al mismo tiempo que mantuvieron un nivel de composición limitado por la necesidad de supervivencia.

Con la generación anterior diezmada por los asesinatos y el exilio, los compositores jóvenes europeos tuvieron que ponerse a la tarea de la construcción de una nueva situación musical más que a la de la reconstrucción, prácticamente imposible, de la anterior. Esa tarea se llevó a cabo partiendo de elementos estéticos del primer tercio del siglo, entre los que destacó pronto la influencia de la manera weberniana de entender el serialismo. La invocación a Anton Webern como nexo entre el antes y el después de las catástrofes de los años treinta y cuarenta se generalizó, alcanzando también a los compositores de la segunda generación posterior a la guerra -como el británico Brian Ferneyhough o el francés Jean Barraqué entre otros-. Muy cerca también de los presupuestos webernianos, Olivier Messiaen, el superviviente del campo de Görlitz, se convirtió en el maestro de una buena parte de los jóvenes compositores: Pierre Boulez, Jean Barraqué, Karlheinz Stockhausen entre otros.

La desconexión generacional favoreció el proceso que había conducido al pluralismo estético en las vanguardias históricas musicales. La expansión del viejo paradigma tonal hasta explotar en diferentes direcciones no tenía vuelta 
atrás. Al contrario, los nuevos compositores se encontraban con un panorama formado por múltiples constelaciones de posibilidades creativas ${ }^{21}$.

A diferencia de los compositores de la primera mitad del siglo, después de la guerra no hubo, inicialmente, ninguna voluntad de tradición, sino todo lo contrario. Sólo la mención a Webern es continua. A pesar del discurso rupturista de Pierre Boulez en relación con Arnold Schönberg y algunos otros similares, las orientaciones básicas de la nueva creación sonora que señalaba John Cage en su célebre Credo de 1939, entroncan con las tendencias de comienzos de $\operatorname{siglo}^{22}$.

Después de la guerra el arte contemporáneo en general, y el sonoro en particular, encontraron mayores facilidades para su desarrollo, al menos en Alemania, Francia e Italia, donde diversas instituciones tanto públicas como privadas fomentaron la investigación y la creación. Esta situación nueva iba a permitir -y a propulsar- una fuerte tendencia experimentalista. El arte sonoro de aquel momento se sabe especialmente efímero, se sabe relativo a unos códigos, a un tiempo, a unas ideas, y se convierte en arte tentativo. Las propias denominaciones dejan claro ese carácter: fragmento, pieza, estudio... La provisionalidad parece establecerse como norma, y no es raro comprobar que un mismo compositor conjugaba varias estéticas de una obra a otra e incluso a lo largo de una misma obra. Incluso el concepto de obra se transformó en diferentes conceptos desde el archimentado de work in progress hasta las propuestas aleatorias.

Muy interesante también ha sido el contraste entre las actitudes y las creaciones de los compositores vanguardistas europeos y los estadounidenses. La denominada Escuela de Nueva York especialmente -John Cage, Morton Feldman, Earl Brown- ha introducido alguno de los conceptos fundamentales de los últimos treinta años: aleatoriedad, happening, minimalismo, «a-finalismo», etc. Incluso Adorno recibe con gusto el soplo libertario de estos compositores frente a los excesos rigoristas de los vanguardistas europeos ${ }^{23}$.

La segunda mitad del siglo ha sido muy dinámica en cuanto a la creación sonora, aunque precisamente en los últimos años han aparecido los primeros síntomas de estancamiento. Frente a compositores como Helmut Lachenmann o Mathias Spahlinger (1944), se imponen tendencias cercanas al pop, al rock,

21 También las tendencias regresivas resultaron fortalecidas después de la tragedia bélica. Desde diferentes perspectivas, el tonalismo ofrecía una posibilidad de reconciliación que la realidad había negado durante años haciéndola improbable en el futuro.

$22 C f$. P. Boulez, «Schönberg est mort», en : Relevés d'apprenti. Paris: Éditions du Seuil, 1966, pp. 265 - 272. R. Kostelanetz, Entrevista a John Cage, tr. J. M. Álvarez y A. Pérez, Barcelona: Cuadernos Anagrama, 1973, pp. 65-70.

23 Th. W. Adorno, «Anotaciones sobre la vida musical alemana», en: Impromptus. GS 17, p. 168. 
al tecno, etc. Se trata del denominado «cross-over»o «no bounds», auténtico «movimiento» que, sin llevar a cabo ninguna síntesis, se contenta más bien con la yuxtaposición de fragmentos de cualquier estilo musical como se puede comprobar en las obras de Heiner Goebbels (1952).

Meine geheimste Absicht war, in der sprachlichen Führung des Aufsatzes unmittelbar so zu verfahren, wie Sie, etwa im Quartett, komponieren ${ }^{24}$

Frente al tópico de un Adorno músico frustrado, como vengo mostrando, lo que nos menciona esta frase es, al contrario, la unión íntima entre lo musical y lo no musical en el joven Adorno. Desde que conoce a Berg va a dedicar mucho tiempo, primero guiado por él y luego en solitario, al análisis musical. Los análisis que lleva a cabo a partir de aquel momento le permitieron perfeccionar su conocimiento de la historia de la composición musical, pero también le ayudaron a profundizar en el conocimiento de la música de su tiempo. De esta forma, a la par que comenzó a analizar las óperas de Wagner y a pensar en un ensayo sobre el compositor, que vería la luz, de hecho, ya en el exilio, se dedicó a analizar la ópera Wozzeck y el resto de las obras de Alban Berg. De esos análisis fue extrayendo tanto consecuencias compositivas, que aplicó en sus propias obras, como consecuencias teóricas, que fue enlazando, en una síntesis peculiar, con sus lecturas filosóficas y literarias. Pero hubo un tercer fruto de aquellos análisis: el tomar la composición musical de su maestro como modelo de escritura. Ese era, según dice, su secreto.

De esa confesión se deduce un dato muy importante. La escritura de Alban Berg no es atonal, aún siéndolo. Es decir, no es lo atonal lo que Adorno pudo llevar a su escritura sobre música ni a su filosofía. Porque palabra y concepto no pueden ser atonales. Hablar de filosofía atonal, como se ha hecho a partir de la boutade de Martin Jay, es dejar en la sombra el procedimiento bergiano, lo que Adorno denominaría como «la transición ínfima». Porque si se intenta hablar de lo atonal aplicado al lenguaje, tendría que prescindirse de la semántica. Lo tonal equivale en pintura a lo figurativo. Tonal y figurativo coinciden en la posibilidad del establecimiento de algunos correlatos significativos que en lo atonal y lo no figurativo, desaparecen. Una escritura atonal sería, en la lengua o en la filosofía, aquella que renunciara a los significados: la experiencia dadaísta, los poemas sin sentido, los juegos onomatopéyicos... En el momento en que la gramática exija un verbo y las palabras mantengan un significado, es inviable mantener la ficción de una filosofía atonal.

24 Carta de Adorno a Berg de 23 de noviembre de 1925, en Theodor W. Adorno-Alban Berg Briefwechsel 1925 - 1935. Herausgegeben von Henri Lonita, Frankfurt: Suhrkamp, 1997, p. 44. 
Entonces, a lo que hay que dirigir la atención es al procedimiento de la variación en la modalidad bergiana. En ella, a diferencia de la variación clásica, en la que los temas y motivos musicales permanecían claramente reconocibles a pesar de las máscaras armónicas, melódicas y rítmicas -en eso consistía el juego musical del tema con variaciones, en un disfraz imperfecto, en un dificultar sin excesos el reconocimiento y la seguridad que conllevaba y conlleva para el oyente el hecho en sí del reconocimiento-, esos temas y motivos, decía, se contraponen y suceden de forma apenas perceptible. Las semejanzas y diferencias conviven en márgenes estrechos -lo que Adorno denomina como «la técnica de los restos» y «la anticipación»- que aseguran una coherencia extrema al discurso pero alejan la inmediatez clásica y exigen una concentración y un rigor por parte del oyente mucho mayores. Así es la escritura adorniana: completa y profundamente bergiana. Y me atrevo a decir que no sólo lo fue en el artículo al que se refiere Adorno en la frase que tomo como título de esta sección, sino que lo siguió siendo hasta el final de sus días, salvo en contados textos que, por diferentes razones, requerían otra disposición formal.

En el cuarteto... ya no existen 'temas' en el antiguo sentido estático. La transición permanente desdibuja toda figura consolidada, la abre al antecedente y al consecuente, la sostiene en el incansable flujo de las variantes, la somete a la primacía del todo. [...] Por ello, la tarea del oyente no es retener los temas y seguir sus destinos sino reconstruir un transcurso musical en el que cada compás, sí, cada nota, se encuentra igual de próxima al punto central. ${ }^{25}$

Basta con que sustituyamos al «oyente» por el lector y se obtiene el rasgo principal de la forma adorniana: que todos los motivos se encuentren igual de próximos a un punto central, es decir, una modalidad de constelación. Esto es, insisto, lo que ya practicaba en los años veinte y lo que va a practicar el resto de su vida.

Aunque Berg no agotó el procedimiento de la variación ínfima, el acento personal en su utilización permite distinguir inmediatamente un mero ejercicio de estilo de un intento compositivo meditado y profundo. Pero la música de Berg, aunque mantiene su contenido de verdad prácticamente intacto, no es la música de hoy. Se puede, claro, recurrir a un estilo Adorno-Berg para la filosofía hoy. Pero la actualización de Adorno no se dirige a establecer una ortodoxia adorniana sino a explorar las posibilidades de ir más allá de Adorno apoyándose en su propia filosofía. Es ese impulso teórico el que nos conduce a los compositores actuales en busca de posibles modelos para la filosofía.

25 Th. W. Adorno, Berg: Der Meister des kleinsten Übergangs. GS 13, p. 393, tr. del autor. 
Es posible que la evolución de la composición y de la filosofía no discurra en paralelo y es improbable que se vuelva a producir una constelación histórica como la que acercó a Adorno y a Berg. Pero no es inútil realizar una exploración en ese ámbito.

Desde el punto de vista formal, las composiciones de los últimos cuarenta años han explorado cientos de procedimientos. No en vano el propio Adorno llegó a escribir un artículo muy interesante, recogido en Quasi una fantasia, que se ocupaba del problema formal, «Vers une musique informelle» ${ }^{26}$. No hay que perder de vista que Adorno, como la mayor parte de los compositores vanguardistas, incluidos los más rupturistas, no han dejado de hablar de música en ningún momento para referirse a sus composiciones por muy alejadas que se hayan encontrado de los conceptos tradicionales. En muchos casos, desde mi punto de vista, se trata de manifestaciones de otro arte que prefiero denominar como creación sonora. Ahí, en ese otro ámbito, es en el que se puede plantear radicalmente la posibilidad de una ausencia total de forma. Pero la música, cualquier música, no es posible sin forma. En cualquier caso, una música sin forma, no sería susceptible tampoco de convertirse en modelo para la filosofía.

Otro rasgo formal de la composición bergiana que, sin duda, gravita sobre la escritura de Adorno es la desmedida, lujuriante superposición de voces y complejos $^{27}$. Adorno no «confiesa» haber utilizado ese procedimiento pero es fácilmente localizable en muchos de sus textos. Él lo analiza y explicita precisamente en relación con la Marcha de las Tres piezas para orquesta op. 6. La simultaneidad de innumerables acontecimientos melódicos es inmediatamente tensión ${ }^{28}$. La dificultad de estas piezas, como la de muchos textos adornianos, se resiste al análisis. La forma tiende a lo informe y los conceptos rozan lo no conceptual del mismo modo que los motivos musicales se diluyen en sus propios contrastes sin que se pueda establecer un catálogo cierto de los mismos.

¿Cuáles serían los modelos musicales actuales para la filosofía? Ya señalaba al comienzo de este artículo una relación de compositores a tener en cuenta en este sentido. Compositores que han abierto nuevas perspectivas para la creación y que han establecido modelos formales que sintetizan elementos literarios, musicales, plásticos e incluso de los medios audiovisuales. El propio Adorno analiza una gran cantidad de música contemporánea, y cita algunos compositores: Boulez, Cage, Ligeti, Maderna, Messiaen y Stockhausen. Incluso intenta establecer una posible continuidad entre los procedimientos de Berg y las obras Gruppen y Zeitmaße de éste último. Pero en el planteamiento que

26 Th. W. Adorno, Escritos musicales I-III, tr. S. Brotons, Madrid: Akal, 2006, pp. $503-549$.

27 Ibid., p. 432.

28 Ibid., p. 433. 
vengo realizando, no se trata de quedarse en Adorno sino de ir más allá. Hay que continuar la investigación para encontrar los compositores y las obras actuales que puedan servir como modelos para la filosofía. Tal vez entre los ya señalados, sean Helmut Lachenmann (1935) y Salvatore Sciarrino (1947) los que se pueden considerar como paradigmáticos.

Tanto Lachenmann como Sciarrino guardan al menos una similitud muy importante con Alban Berg: han compuesto sendas óperas que, pésimamente recibidas todavía, marcan un hito en la comprensión del género operístico, por una parte, y, por otra, marcan posibles direcciones para el futuro. Das Mädchen mit den Schwefelhölzern de Lachenmann, del año 2001, y Luci mie traditrici, de Sciarrino, igualmente de 2001, coinciden de nuevo con el Wozzeck de Berg en el hecho de que sus textos han sido también compuestos y reescritos por los propios compositores. En ambas óperas se proponen nuevos procedimientos vocales e instrumentales, una nueva revisión inherente de la escenografía y, al mismo tiempo, un cuestionamiento del lenguaje mismo. En el caso de Lachenmann, la palabra emerge a duras penas de la onomatopeya y de los ruidos musicales. En el caso de Sciarrino, el límite directo y permanente de la palabra es el silencio que a duras penas permite que el oyente capte el texto, tal es su densidad y su articulación discursiva. La posibilidad del silenciamiento del arte, que también Adorno constata permanentemente en sus reflexiones, no es sólo una cuestión teórica sino que está inmersa en el corazón mismo de las obras. ¿Cómo pueden estas composiciones llegar a convertirse en modelo para la filosofía? Sólo el análisis detallado de estas óperas y del resto de la producción de estos dos compositores así como de sus textos teóricos puede iluminar el camino de un filosofar que no se conforme con modelos periclitados ${ }^{29}$.

29 H. Lachenmann, Musik als existentielle Erfahrung, Wiesbaden: Breitkopf und Härtel, 2004. S. Sciarrino, Le figure della musica da Beethoven a oggi, Milano: Ricordi, 1998. 